\title{
CONFIGURING CONSUMER-DEMAND DRIVEN SUPPLY NETWORKS
}

\section{- Example from the Made-to-Measure Fashion Sector}

\author{
Philipp Schiegg ${ }^{1}$, Antonio Lucas Soares ${ }^{2}$, Amit Garg $^{1}$, Robert Roesgen ${ }^{1}$, \\ Volker Stich ${ }^{1}$ \\ ${ }^{I}$ Research Institute for Operations Management (FIR) \\ Aachen University of Technology \\ Pontdriesch 14/16, D-52062 Aachen, GERMANY \\ [sg,ga,roe,st]@fir.rwth-aachen.de \\ ${ }^{2}$ INESC Porto \\ Instituto de Engenharia de Sistemas e Computadores do Porto \\ Rua Dr. Roberto Frias, $n^{\circ} .378,4200-465$ Porto, PORTUGAL \\ als@fe.up.pt
}

\begin{abstract}
The purpose of this paper is to present a concept for configuring dynamic and ready-to-implement supply network structures. This concept is based on a (real) business case from the fashion industry where order, logistics and production management processes are entirely consumer-driven. Only after the consumer has configured and customised his made-to-measure fashion product and placed his order, the actual constellation of partners in the supply network is determined and business processes initiated. The focus of the paper is on the methodological approach of defining and modelling the underlying business model.
\end{abstract}

\section{INTRODUCTION}

The zeal for customised products is the driving force for many industries including the fashion and textile industry where various alternatives and methods for implementing mass customisation are being used actively. However, the process of managing the dynamic supply chain assembled in response to a specific customer order is becoming more complex and challenging. The research project MyFashion.eu addresses these challenges of logistics and order management in dynamic value constellations (Schiegg et al. 2002). The vision of MyFashion.eu is to establish an innovative business model that aims at providing integrated extended 
fashion products which will add value to the consumer. One of the innovations of MyFashion.eu is to provide consumers not only with single fashion products, e.g. as in traditional shops, but enable consumers to combine different products and services in order to obtain a new extended and customised product. Only after the consumer has configured and customised his made-to-measure fashion product and placed his order, the actual constellation of partners in the supply network is determined and business processes initiated (see Figure 1).
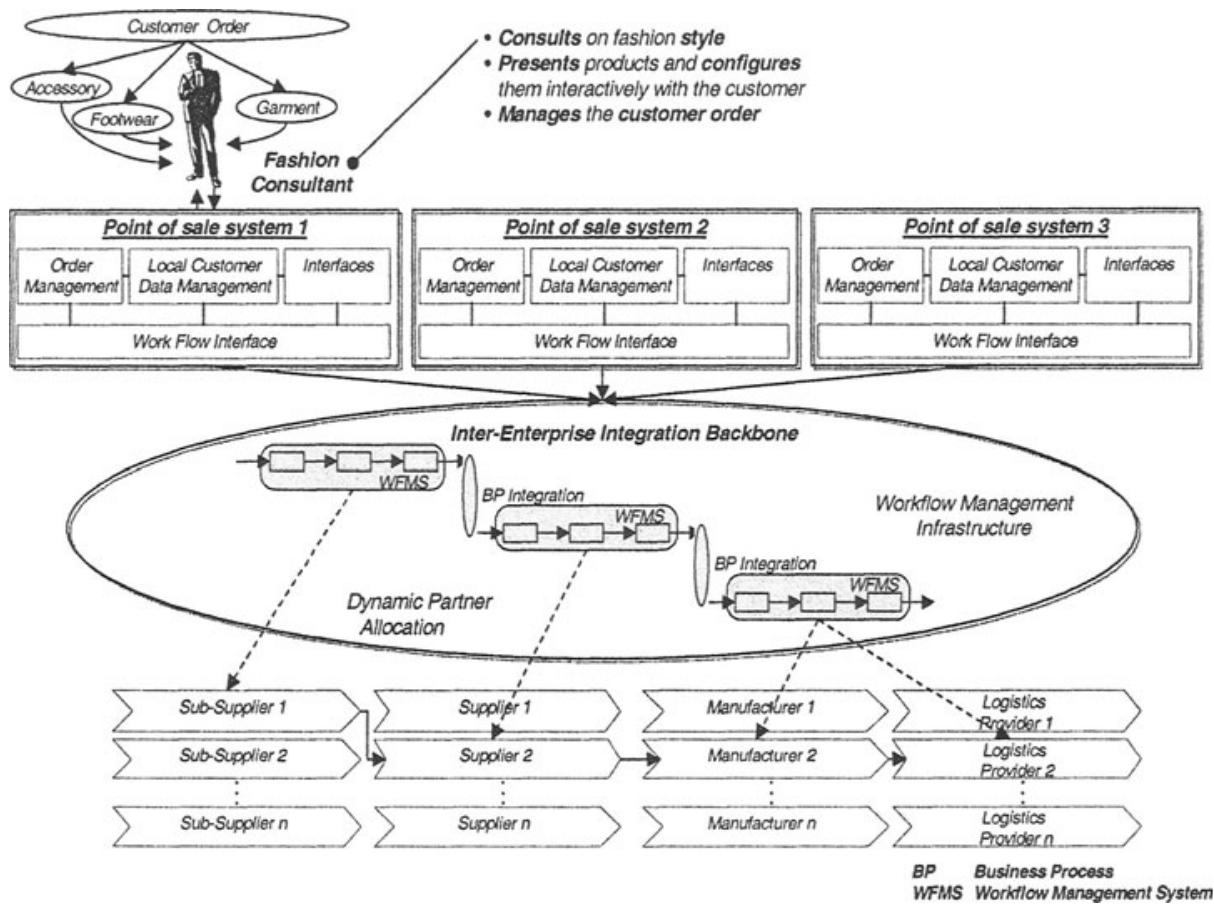

Figure 1 - Concept of a Consumer-Demand Driven Supply Network

To provide customers with customised and integrated fashion products, the business actors need to streamline their processes and adapt themselves to fulfil the customer requirements. The main business actors include the retailer, manufacturer and the fabric suppliers. The complete order fulfilment process needs to be developed, standardized and accepted by all the partners as the means of doing business. This work aims to develop such generic business processes and models, which can help different business actors to come together for the fulfilment of a customer order. These business models define the processes, interactions between different business actors and the legacy information systems. One of the key challenges in coming up with these business models is to identify the role of various business actors. With the possibility of different actors fulfilling the same role, it is a matter of management principles, mutual understanding and convenience as to who takes these roles. The business models define the underlying processes and the competences of the individual actors to fulfil the customer order. 


\section{BUSINESS MODELLING}

Business modelling is a process that aims at improving the way we understand the current or future business architecture of an enterprise. It produces a set of conceptual models (business architecture models) that convey a simplified view of a business. The business architecture model functions as the plan for conducting a business and acts as the basis for decision-making. It enables a better understanding of the key mechanisms of the existing business and facilitates experimentation with new business concepts. Finally, business architecture models act as the basis for creating and improving suitable information systems that support the business. Modelling business architecture involves answering questions such as:

- How do the different actors interact?

- What activities are the parts of their work?

- What are the ultimate goals of their work?

- What other people, systems or resources are involved that do not show up as actors to this specific system?

- What rules govern their activities and structures?

- Are there ways actors could perform more efficiently?

Business architecture modelling is a relatively new area even thought that some modelling concepts where established more than two decades ago. In the last few years, the business process focus of enterprise engineering together with the expansion of the e-business paradigm demanded for effective enterprise modelling methods.

Regardless the main purpose of the business architecture model it is necessary to decide on the perspectives that are necessary to consider in order to represent adequately a business architecture. This is usually called modelling "views". Therefore, the adoption of a given modelling framework depends very much on the business architecture aspects that must be analysed and managed with the support of models. There are a number of modelling frameworks or (modelling methods) that provide a comprehensive set of tools from several modelling views. It is not a goal of this paper to detail this issue (regarding enterprise modelling methods in general see Fraser, 1994; regarding the organizational view of enterprise modelling methods see Soares, 2000; for a specific framework see for example Scheer, 1999; on business process modelling see Becker et al., 2000).

The business model developed in MyFashion.eu domain for various business actors addresses these issues. The focus in developing these business models is two fold: first, to define distinct processes throughout the supply chain and to assign the responsibility of these processes to one of the business actors; and second, to synchronise these processes across the complete supply chain.

It is important to clearly mark the roles and responsibilities of different partners participating in a supply chain. When supply chains are assembled dynamically to fulfil a customer order, then, all the processes of all partners should be synchronised with each other. If there are overlapping processes or conflicts, then it becomes difficult to assemble a supply chain dynamically based on the customer request. Hence, it becomes critical to establish and streamline the processes across all the partners. It has been also identified that it is difficult to generalize all the retailer business processes into a generic retailer business model. There are invariably processes which are dependent on organisation's policy and methodology of doing 
business. Thus we identified the first two levels or hierarchy of processes which stood common to all the business actors. Only when we look at the underlying detailed processes and activities there are specific customisations and deviations.

\section{MODELLING THE BUSINESS ARCHITECTURE FOR THE MYFASHION.EU SUPPLY CHAIN}

\subsection{Approach}

Within the context of the MyFashion.eu RTD project, the UML modelling method was adopted as standard. Regarding business architecture modelling a complementary method involving specific business extensions was adopted (Eriksson and Penker, 2000). UML includes a set of well known and easy to learn diagrams that, together with established and/or customised procedures, enable a representation of the business processes adequate to several types of analysis. Another important issue is the object-oriented feature of UML. Among the characteristics of the object-oriented perspective, one should highlight here the generalisation/specialisation flexibility, enabling the construction of models with a variable level of detail. This can result in models generic enough to be the reference for several companies from one side, and to be easily specialised for each application from the other side. This perspective pervades all the UML diagrams and is well suited to the purpose of reference models. The four different views proposed by Eriksson and Penker include the business vision, business process, business structure and business behaviour. These views represents most of the aspects related to an organisation namely the goals, processes, resources, organisational structure, interactions and state chart diagrams.

The business architecture models developed for MyFashion.eu are encapsulated in two generic scenarios which deal with different levels of customisation and flexibility in providing the products and services to the customer. These scenarios portray the future vision for the made-to-measure business processes but take into account the existing business realities and business practices of the industrial partners in the project.

\subsection{Two Scenarios - Instantiations of the MyFashion.eu Business Model}

Scenario 1 deals with those supply chain partners who work with primarily static supply chains but provide the complete product customisation options to the customer. In this scenario, the term "primarily static supply chain" means that business relations between the different network partners, e.g. retailers, manufacturers, and suppliers, are already well established. Fashion products that an end consumer can choose from come as a bundle of style and material options. For example, a producer of business suits may only offer his products with a predefined set of different fabrics from a predefined set of suppliers. Thus, in this scenario, if an end consumer selects a specific product, he automatically selects the supply chain, i.e. manufacturer as well as its supplier, that provides him with the product (see Figure 2). 
Scenario 2 deals with the more dynamic oriented supply chain, where an end consumer is given more flexibility in designing his product. For example, in contrast to scenario 1, an end consumer might now choose a product style from one manufacturer and select the fabric from a supplier that does not have to have an already established business relationship with the manufacturer. Of course, this scenario requires that a manufacturer is able and willing to process any fabric of any supplier. As a consequence, retailers now have the flexibility and responsibility to choose the business partners according to the customer order. Non-linear communication occurs, as a retailer has to communicate not only with a manufacturer but also with its suppliers. Alternatively, a communication and coordination platform could handle these processes. This functionality is provided and supported by the MyFashion.eu platform to be developed.

Scenario 1

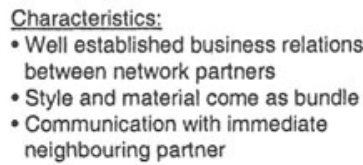

Retailers

Manufacturers

Suppliers

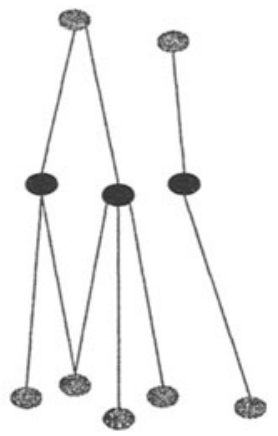

Scenario 2

Characteristics:

-Well established and ad-hoc business

relations

- Style can be selected independent from

material

- Non-linear communication

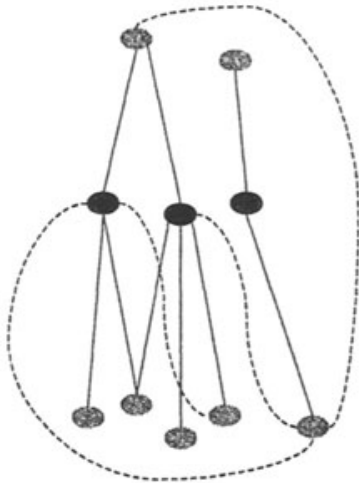

Predefined, established business relation

Ad-hoc business relation

Figure 2 - Business Model Instantiation - Two Scenarios

\subsection{Modelling the Two Scenarios}

The two basic scenarios serve as a first draft of the business model. As a next step, the authors refine the business model by using the UML modelling approach described above (see section 3.1). In the following, the approach of modelling the process models as part of the business process view is described.

A three-level hierarchy of processes is used to represent the underlying processes of the business actors. Level one and two of the process hierarchy depict generic processes that are common to all business actors, whereas level three portrays the detailed processes and activities that are distinctive to each business actor, e.g. retailer, manufacturer or supplier (see also Figure 2). As such, level one and two of 
the process hierarchy represent a business process reference model for the made-tomeasure fashion order management.

Three basic and main processes have been identified by the authors on the second level of the process hierarchy:

- Order inquiry and acceptance,

- Order fulfilment (production and delivery), and

- Customer information service.

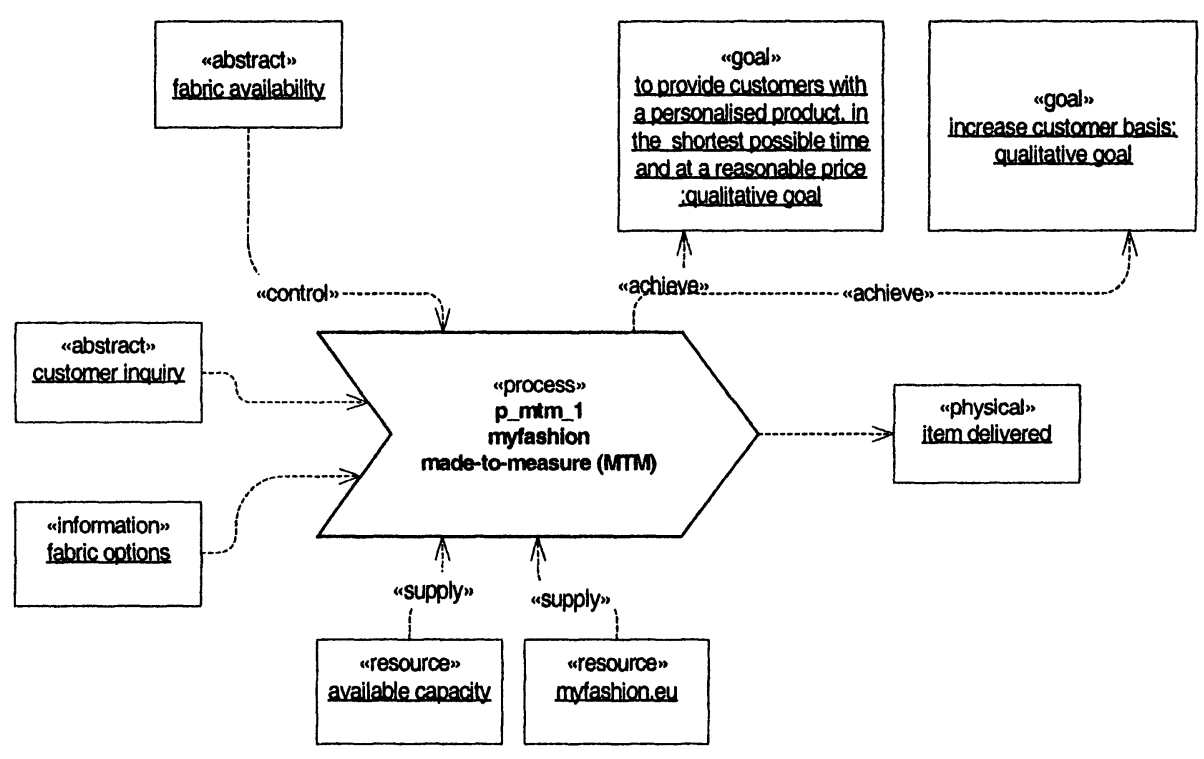

Figure 3 - Generic Process Model (Level 1)

Here, the order inquiry and acceptance process deals with transforming a customer inquiry or request into an order that is processed subsequently, e.g. an inquiry from a retailer to a manufacturer whether a product can be produced (capacity check) and whether all materials (e.g. fabrics) are available in order to produce the order. The manufacturer accepts and confirms the order to the retailer.

The order fulfilment process covers all activities related to the physical production and distribution of the product and its components along the supply chain. The customer information service process can be viewed as a cross section process of delivering information on any kind of request, e.g. an inquiry on the status of an order or delivery process from an end consumer to the retailer, or from the retailer to the manufacturer.

These three main processes are modelled for each business actor, and, subsequently, integrated into one business model for each scenario. The same approach is used to model the other views, namely business vision, business structure and business behaviour view for the two scenarios. 


\section{CONCLUSION}

In the European fashion sector that is known for its fragmentation, MyFashion.eu addresses the need to increase the competitiveness of small and medium sized enterprises (SME). The business case presented in this paper demonstrates SMEs' necessity to operate more and more in a make-to-order and/or made-to-measure environment. Key to this is a conception as well as a system to manage these supply networks that are assembled to meet individual consumer demand.

The focus of this paper is to present an approach for defining and modelling a reference business model for this business case. The approach taken in this paper i.e. combining different approaches (e.g. scenario description) and existing modelling techniques (e.g. UML) - provides to be a useful support in fulfilling this task and to enable software development that follows the modelling phase.

\section{Acknowledgements}

This work is sponsored by the European Commission through IST-2001-32560 "MyFashion.eu - Added Value for the Consumer Through Integrated, Extended Fashion Products". The authors wish to acknowledge the European Commission for their support.

\section{REFERENCES}

1. Becker J, Rosemann M, Uthmann, C. Guidelines of Business Process Modeling. Business Process Management: Models, Techniques, and Empirical Studies. Van der Aalst et al., ed. Berlin: Springer 2000.

2. Eriksson H.E., Penker M. Business Modeling with UML - Business Patterns at Work. John Wiley, Chichester, 2000.

3. Fraser J., Machintosh A. Enterprise State of the Art Survey, The Enterprise Consortium, September 1994. The University of Edinburgh, http://www.aiai.ed.ac.uk.

4. Scheer, AW. Business Process Modeling. Berlin: Springer 1999.

5. Schiegg P., Garg A., Roesgen R. MyFashion.eu - Logistics and Order Management in Dynamic Textile and Apparel Supply Networks. In: Stanford-Smith, B.; Chiozza, E.; Edin, M. (Hg.), Challenges and Achievements in E-business and E-work, S. 2002; 1299-1306. IOS Press, Amsterdam, Berlin, Oxford, Tokyo, Washington D.C. Available at http://www.myfashion.org.

6. Soares A. L. A social and organisational ontological foundation for Enterprise Modelling. in IFAC Symposium on Manufacturing Modelling, Management and Control. Patras, Greece. 2000.

7. Soares A., Carneiro L., Carneiro D. Making effective the introduction of e-business in SME: a reference model approach. Proceedings of the CARS\&FOF 2002 International Conference, 2002. 